\title{
Latex allergy in dentistry: clinical cases report
}

\author{
Daniela Prócida Raggio ${ }^{1}$, Lucila Basto Camargo ${ }^{2}$, Giselle Maria C C Naspitz ${ }^{3}$, Clarissa Calil Bonifacio ${ }^{4}$, \\ Gabriel Tilli Politano ${ }^{5}$, Fausto Medeiros Mendes ${ }^{6}$, Flavia Kiertsman ${ }^{7}$
}

${ }^{1}$ DDS, MS, PhD, Asssitant Professor, Departamento de Ortodontia e Odontopediatria, Faculdade de Odontologia, Universidade de São Paulo.

${ }^{2}$ DDS, MS, Universidade Paulista; PhD Student, Departamento de Ortodontia e Odontopediatria, Faculdade de Odontologia, Universidade de São Paulo.

${ }^{3}$ DDS, MS, PhD, Universidade Paulista.

Flavia Kiertsman, DDS, MS, Uniararas.

${ }^{4}$ DDS, MS, PhD Student ACTA - Academic Centre for Dentistry Amsterdam.

${ }^{5}$ DDS, MS, São Leopoldo Mandic; PhD Student, UNICAMP - Universidade de Campinas.

${ }^{6}$ DDS, MS, PhD, Assistant Professor, Departamento de Ortodontia e Odontopediatria, Faculdade de Odontologia, Universidade de São Paulo.

${ }^{7}$ DDS, MS, Uniararas.

Correspondence:

Daniela Prócida Raggio, DDS, MS, PhD,

Departamento de Ortodontia e Odontopediatria,

Faculdade de Odontologia, Universidade de São Paulo.

Av. Lineu Prestes, 2227

Cidade Universitária - 05508-000

São Paulo-SP - Brazil

e-mail:danielar@usp.br

\author{
Raggio DP, Camargo LB, Naspitz GMCC, Bonifacio CC, Politano GT, \\ Mendes FM, Kiertsman F. Latex allergy in dentistry: clinical cases report. \\ J Clin Exp Dent. 2010;2(1):e55-9. \\ http://www.medicinaoral.com/odo/volumenes/v2i1/jcedv2ilp55.pdf \\ Article Number: $678924 \quad$ http://www.medicinaoral.com/odo/indice.htm \\ (C) Medicina Oral S. L. C.I.F. B 96689336 - eISSN: 1989-5488 \\ eMail: jced@jced.es
}

\begin{abstract}
Generally natural rubber latex (NRL) allergy is detected after some exposition to the material. As NRL is commonly found in different materials used daily in dental clinic, the allergy can be manifested in the pediatric dentistry clinic. The first clinical manifestation can be smooth but also severe, therefore it is important to know different manifestations and how to prevent them. Objective: Report two clinical cases of natural rubber latex allergy in children and to present the safety measures that must be taken during clinical assistance, as using metallic saliva ejector, vinyl gloves for the treatment procedures and as an option to rubber dam. Cases Report: Case 1- Patient presented body swellings after contact with latex. Case 2- Patient presented skin eruptions and urticaria after contact with balloons suggesting possible NRL allergy. Conclusions: The precautions must always be taken during the dental treatment of natural rubber latex allergic patients in order to achieve satisfactory results by avoiding dermatitis or even anaphylactic shock.
\end{abstract}

Key words: Latex allergy, pediatric dentistry. 


\section{Introduction}

Natural rubber latex is found in different materials used daily in dental clinic, such as in gloves, rubber dam and in others products that children are put in contact during treatment, such as pacifiers, baby bottle, balloons, among others (1). Despite coming from a tropical tree, the "Hevia brasilienses", the manufacturing process of the NRL comprises the addition of many chemical products to the raw material. Those additions are made in order, to determine the texture, color and elasticity (2) of the final product. For that reason the likelihood of NRL allergic patient to develop hypersensitivity reactions during or after dental procedures is high.

The NRL gloves can also present some organic agents, such as funguses, liquens and different kinds of proteins. It can also be manufactured without proper hygiene conditions. It have been reported even a case that a dentist found a fly processed into the glove (3).

The gloves are used by the dentist to reduce crossed infection, therefore, protecting both the patient and the dentist. The use of gloves is also necessary when chemical products used for cleaning and disinfection are employed (4).

Over $29 \%$ of dentists reported dried and sore hands after using latex procedures gloves. Despite such symptoms of contact dermatitis are considered by most dentists as a simple reaction, recently, the reports of "real allergies" have risen in number (3).

An evaluation of NRL allergy prevalence among 34 professionals in a dental clinic found out that $12 \%$ of them presented some NRL-related allergy demonstrated by medical tests (5).

There are three common cases of reactions to latex exposure: irritative dermatitis and hypersensitivity of type IV and type I, being the latter the most serious reaction. The irritative dermatitis, a non immunological reaction, is the most common effect and refers to the process that occurs when the superficial skin presents signs of dryness or irritation when in contact with NRL. Consequently, due to skin rash, the NRL proteins can be easily absorbed, worsening the problem.

The type IV hypersensitivity is an immunological, late and localized reaction. Such a symptom is motivated by the body response to the chemical additives used in NRL manufacturing process. Between 48 and 96 hours after the contact, erithema, itching and even bubbles similar to the irritative dermatitis can be found. Those symptoms can continue for weeks or months, leading to bacterial contamination (6). In order to differentiate the IV hypersensitivity from the irritative dermatitis the diagnosis should be done through allergic contact test.

The type I hypersensitivity is of rare occurrence. Additionally, it is an immediate reaction and modulated by the IgE, differently of the type IV hypersensitivity. Similarly to after bite insect reaction, medicines or food intake, it occurs from 2 to 3 minutes after contact and is caused by NRL proteins, rather than to chemical additives (7). Symptoms range from local allergy signs, dizziness, laryngeal swelling, palpitation, bronchoespasm, low blood pressure, anaphylaxis to death in extreme cases (8).

The variation of quantity and quality of proteins present in NRL products determines the different types of allergic reactions (9).

Repeated exposures to an antigen can increase the sensitivity to the agent (9). Burke et al. (10) reported 3 clinical cases of latex glove allergy, confirmed by allergic tests, after dental procedures. In one of the cases, the patient reported asthma, eczema and allergic reactions after eating melon, watermelon, banana, chocolate and aspirin intake (7). The patient history can be used as an auxiliary instrument to avoid allergic problems.

Some patients should be considered as high risk group, such as patients with spina bifida, urologic alterations, premature birth, mental alterations, cerebral palsy and patients who had undergone multiple numbers of surgeries. All professionals that use latex gloves should be considered as high risk for allergic reaction $(8,11)$. Any person with suspect of allergy should consult an allergist or dermatologist to have allergic tests done.

Patients considered sensitive to NRL should receive special care to guarantee a safe dental treatment. Huber and Terezhalmy (12) stated that such individuals should be treated with vinyl gloves beyond being the first patients assisted in the day to avoid high levels of latex proteins in the dental office air. In order to facilitate the rubber dam technique for allergic patients, Ireland (13) suggested the use of vinyl gloves after having them cut in the half and having the fingers removed. This way, it is possible to obtain a dam similar to the regular rubber dam, nevertheless, with less elasticity.

This report describes two clinical cases of natural rubber latex allergy patients' treatment, demonstrating simple precautions that must be taken for adequate and safe results.

\section{Cases report}

\section{Case 1}

Patient A.J.J.M., female, nine years old. During the anamnesis, the mother mentioned that the child presented NRL allergy. The first contact with latex happened on her first birthday party through a balloon, resulting in swellings on her body. According to mother's report, the child presented three other strong reactions after contact with latex gloves and elastic band when she was submitted to laboratorial blood tests which proved the NRL allergy. Her mother also said that she could not use medicines containing acetaminophen or aspirin, besides presenting dust allergy and bronchitis crises.

In order to obtain a safe treatment, vinyl gloves were 


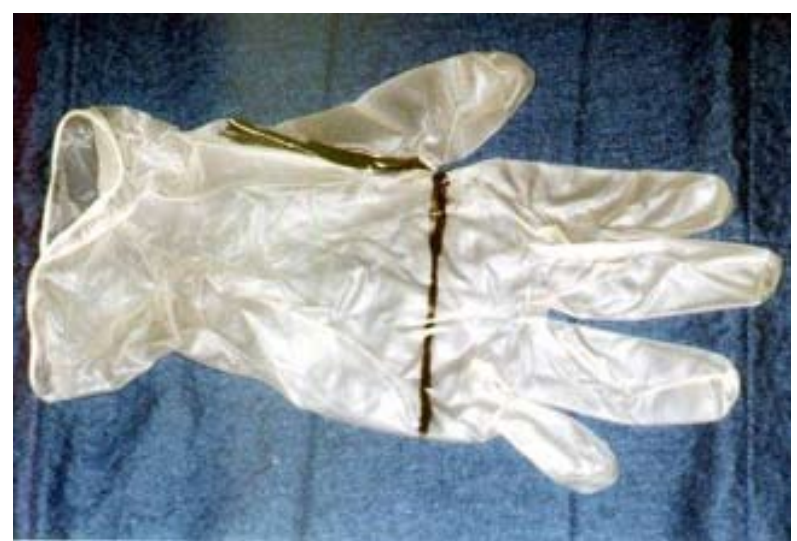

Fig. 1. Vinyl glove used for dental treatment.

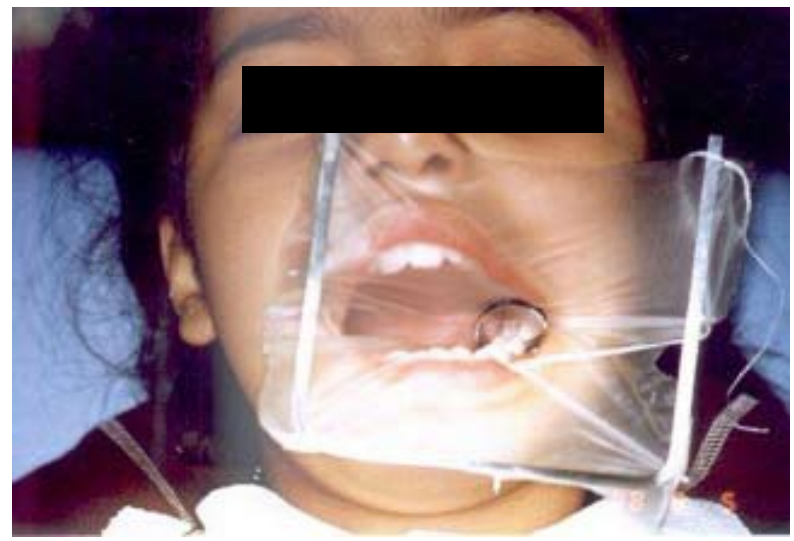

Fig. 2. Using vinyl gloves as an alternative to rubber dam. technique.

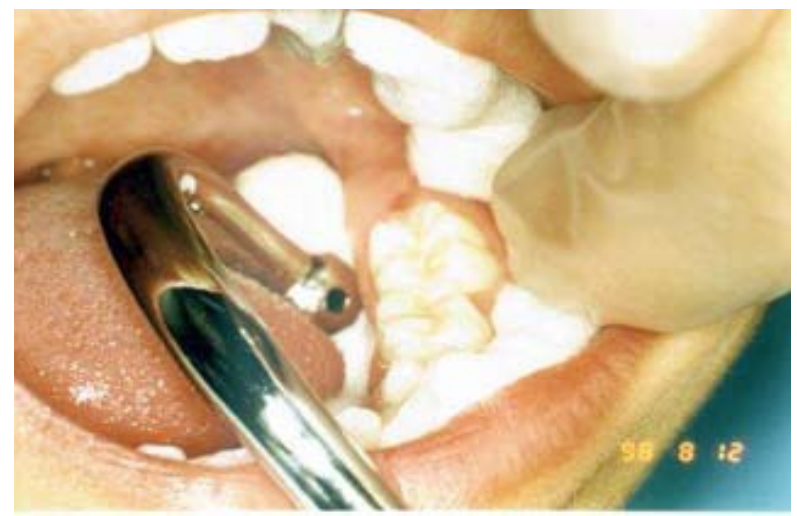

Fig. 3. Use of metallic saliva ejector.

used for professional safety by the dentist and to create an alternative rubber dam technique. No other containing latex materials were used (Fig. 1-3).

Case 2

Patient B.C.B., female, five years old reported dental pain when chewing. During anamnesis, skin eruptions and urticaria were reported when the child had contact with balloons suggesting possible NRL allergy. However, after laboratory examinations, the result was negative.

In spite of the negative allergic results, but taken into

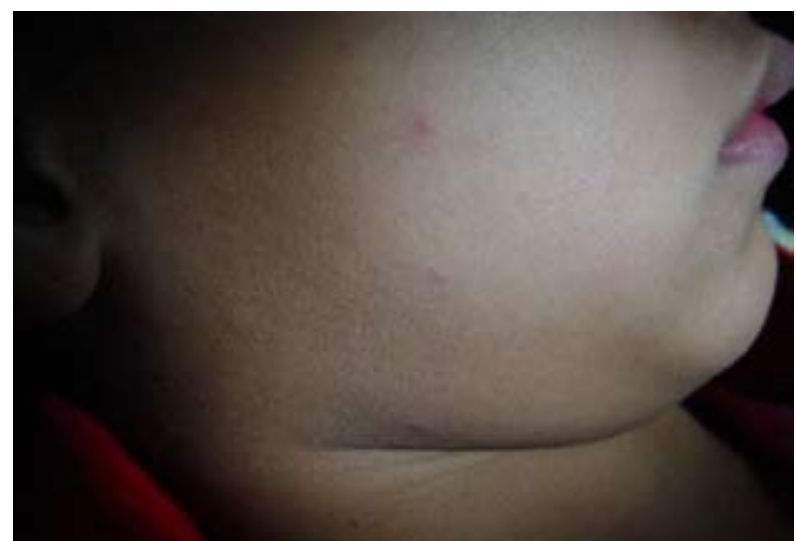

Fig. 4. Skin reaction after latex contact.

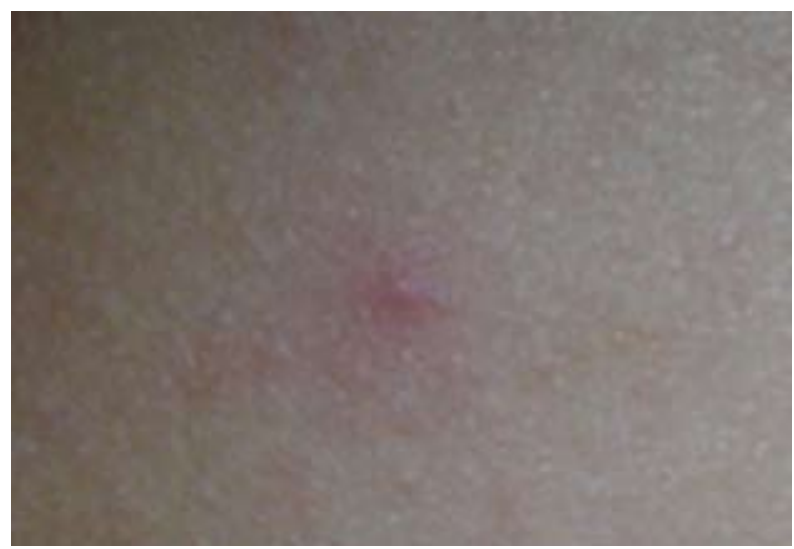

Fig. 5. Reaction after latex contact, in spite of laboratory exams negative for NRL allergy

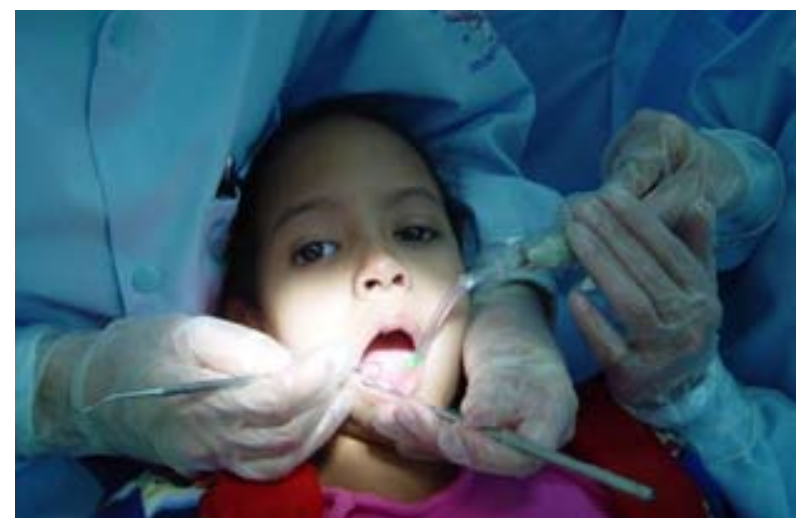

Fig. 6. All materials and instruments should be latex-free

consideration the reactions noticed and reported by the mother, the professional's choice was to use vinyl gloves for the treatment (Fig. 4-6).

\section{Discussion}

To be considered safe, dental treatment needs some precautions, which sometimes are neglected by dentists. Obtaining a credible medical history is the first step for the NRL allergic patient's diagnosis.

During anamnesis the patient or responsible should be asked about the risk of using materials containing NRL. 
According to Mehra and Hunter (11), people who suffer from spina bifida, urologic modifications, premature birth, mental retard, cerebral paralysis or patients who passed through many surgeries are more sensitive to latex allergy. Therefore, patients presenting rhinitis, asthma or food allergy should be informed that atopic, hands dermatitis and certain food allergies are risky factors when associated to latex.

Duration and magnitude of any symptom of allergic reaction, local or systemic, should also be investigated. Reports of dermatitis, swelling, redness and irritation confined to latex contact area are important to differentiate patients with hypersensitivity type IV or type I (12).

After medical diagnosis of irritant dermatitis and hypersensitivity type IV, the dental treatment should be done avoiding all NRL products (1). If there is doubt regarding to the presence of NRL in the product, the manufacturer should be contacted. Type I hypersensitivity treatment is based on severe degree reaction. Mild reactions can be treated with antihistamines and corticosteroids and case of asthmatic reaction with bronchodilator in addition to the removal of the natural rubber latex contact (6).

In case 1, patient was diagnosed with irritative dermatitis after exposed to NRL allergy test, which required special care, such as alternative latex rubber dam, metallic saliva ejector and attention with anesthetic tube. The use of alternative latex rubber dam with vinyl glove should be done (13). By 1997, Martin et al. (14), selected 17 brands of rubber sheets in order to exam proteins and compare with those known to be allergenic. All sheets showed a protein with molecular weight 14 , potentially allergenic, and were found up to 9 different types of proteins on the same sheet.

The gloves used by dentists are made of latex, therefore other options are preferable when treating allergic patients. Hamann et al. (15) affirm that there are more than 200 types of products added to latex gloves, among them some very allergenic, such as accelerators and antioxidants, that can cause type IV hypersensitive.

On the other hand, it is common that parents report that the child is allergic to some substance, food, animals or other, even without the allergic test, because, at some point they have observed skin reactions (usually eruptions) in contact area. In case 2, the patient had no medical diagnosis of latex allergy, but the mother reported that contact with any material containing NRL caused face swelling. Until the final diagnosis is defined by allergic tests, dental professional should avoid using latex containing materials, because even if the hypersensitivity previously presented was mild, for example irritative dermatitis, it is known that repeated exposures can increase the sensitivity (9).

Antihistaminic or corticosteroid medications were not prescribed for the reported patients because there was no diagnosis of type I hypersensitivity. It is noteworthy that pre-medication can reduce the severity of allergic response; however, this should never be considered as an alternative to removing latex contact (6).

The desensitization method for treatment of NRL allergic patients is considered safe and effective. This method is based on contact removal of all containing latex materials and food that may cause allergic reaction (kiwi, nuts, tomatoes, bananas, among others), leading to controlled contact, initially for 10 seconds, increasing by 1 hour, for 1 year. But Taylor and Erkek (8) pointed out that this method should not be applied to type I allergic reactions.

When adequate precautions are taken during treatment of latex allergic patients, the result is satisfactory, avoiding dermatitis and anaphylactic shock, which despite being rare, can happen.

The latex is a natural rubber widely used in dental clinics' routine, which can lead to different types of allergic reactions in sensible patients. Moreover, it presents chemical additives that enhance the development of the hypersensitivity reactions. When treating potential latex allergic patients, professional must ensure some relatively simple precautions to avoid problems in the treatment.

\section{References}

1. Shojaei AR, Haas DA. Local anesthetic cartridges and latex allergy: a literature review. J Can Dent Assoc. 2002;68:622-6.

2. Roy A, Epstein J, Onno E. Latex allergies in dentistry: recognition and recommendations. J Can Dent Assoc. 1997;63:297-300.

3. Clappison RA. Changing the course of latex allergies. Oral Health. 1998;88:17.

4. Hamann CP, Turjanmaa K, Rietschel R, Siew C, Owensby D, Gruninger SE, et al. Natural rubber latex hypersensitivity: incidence and prevalence of type I allergy in the dental professional. J Am Dent Assoc. 1998;129:43-54.

5. Safadi GS, Safadi TJ, Terezhalmy GT, Taylor JS, Battisto JR, Melton AL. Latex hypersensitivity: its prevalence among dental professionals. Am Dent Assoc. 1996;127:83-8

6. Hamann CP, Rodgers PA, Sullivan K. Allergic contact dermatitis in dental professionals: effective diagnosis and tretament. J Am Dent Assoc. 2003;134:185-94.

7. Warshaw EM, Nelson D. Prevalence of evaluation for latex allergy and association with practice characteristics in United States dermatologists: results of a cross-sectional survey. Am J Contact Dermat. 2001;12:139.

8. Taylor JS, Erkek E. Latex allergy: diagnosis and management. Dermatol Ther. 2004; 17: 289-301.

9. Snyder HA, Settle S. The rise in latex allergy: implications for the dentist. J Am Dent Assoc.1994;125:1089-97.

10. Burke FJ, Wilson MA, McCord JF. Allergy to latex gloves in clinical practice: case reports. Quintessence Int. 1995;26:859-63.

11. Mehra P, Hunter MJ. Latex allergy: a review of considerations for the oral and maxillofacial surgeon. J Oral Maxillofac Surg. 1998;56:1426-30.

12. Huber MA, Terezhalmy GT. Adverse reactions to latex products: preventive and therapeutic strategies. J Contemp Dent Pract. 2006; 7:97-106.

13. Ireland EJ. Modification of a vinyl glove into a dental dam for patients sensitive to latex rubber. Oper Dent. 1997;22:186-9.

14. Martin KM, Martin MV, Birss AJ, Field EA. The protein content of dental rubber dams. J Dent. 1997;25:347-50. 
15. Hamann B, Hamann C, Taylor JS. Managing latex allergies in the dental office. J Calif Dent Assoc. 1995;23:45-50. 